\title{
GOLd COATINGS FOR FLUXLESS SOLDERING
}

\author{
David M. Jacobson and Giles Humpston, \\ GEC Hirst Research Centre, Wembley, Middlesex, U.K.
}

\begin{abstract}
Gold coatings play an important role in flux-free joining in a vacuum - a method widely used in electronics fabrication. In this process, the gold coating provides a substitute for the flux, ensuring that the surfaces of the joint are oxide free and solderable.
\end{abstract}

\section{Introduction}

Most of the materials used in the electrical and electronics industry are not readily wetted by common solders, including those based on lead-tin alloys. This is largely due to the presence of oxides on the exposed surfaces of the bare materials [1]. For certain metals, such as copper, this problem may be overcome by the application of active fluxes to the region of the joint, capable of removing the oxide coating. However, the residues left by fluxes generally cause corrosion and these are not always easy to completely remove. Fluxes are especially undesirable where the soldered assemblies are required to serve in a vacuum environment and must therefore be free of corrosive and volatile materials. Moreover, where it is required for the soldering operation to be carried out in a vacuum or in a protective atmosphere, fluxes should be avoided because they can foul and even damage furnace and vacuum equipment.

Furnace soldering under vacuum or protective atmospheres is often preferred for the fabrication of high-integrity assemblies. This method can be easily automated for the production of large numbers of small articles that are selflocating or readily jigged. The heating cycle can be carefully controlled and the fact that the heating is not localized

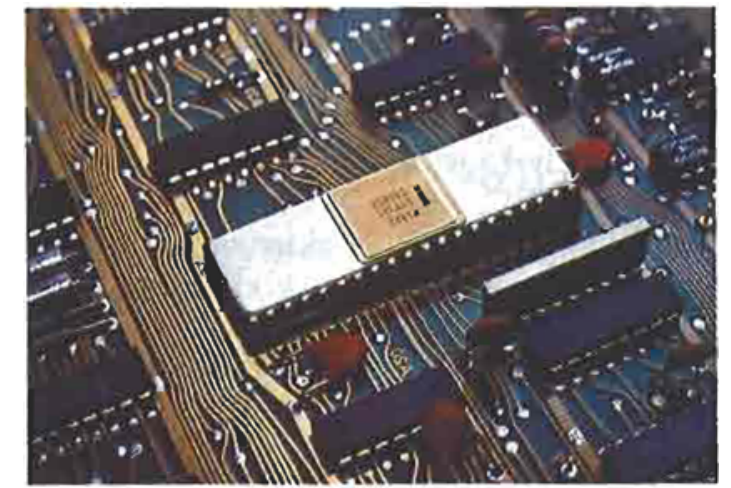

A gold-plated printed circuit board. In high-reliability applications, gold platings are used in preference to tin to provide a highly solderable surface and also to protect the underlying copper tracks from corrosion during storage prevents distortion and other problems associated with the local heating produced by torches or soldering irons.

For soldering in a vacuum or protective atmosphere, gold coatings are often employed as a substitute for fluxes. Experience has shown that gold is adequately wetted by most molten solders in such an environment. This metal possesses other properties that make it useful as a coating on electrical and electronic components, in particular excellent corrosion resistance and high electrical conductivity. However, there are also problems associated with its use as a solderable coating, namely the susceptibility of joints to embrittlement. On account of these features, a large number of papers have been written on the subject of gold solderable coatings, including review articles $[2,3,4]$. These publications and reports almost all relate to situations in which goldcoated components are soldered in air using a non-or mildly-activated rosin flux, and mostly where the solder is applied by dipping. By contrast, the applications being considered here involve vacuum and protective atmosphere soldering without fluxes being used and the solder is introduced in a fixed amount as a foil or wire preform placed within the joint. By introducing a predetermined quantity of solder, it is possible to satisfy design constraints on composition of the alloy in the soldered joint. 
This review selects and critically assesses the information in the literature that is of relevance to vacuum and protective atmosphere soldering. Because most of the published information is concerned with tin-lead solders, their behaviour in relation to gold metallizations will be described first and this will then be compared with the characteristics of other solders on gold-coated substrates. Cadmium- and zinc-containing solders are excluded from consideration because these volatile elements are incompatible with a vacuum or reduced pressure atmosphere. General conclusions will then be drawn regarding the use of gold coatings in the context of vacuum and protective atmosphere soldering.

\section{Solders Based on Tin}

\section{Tin-lead}

A specific feature of tin-lead solders is the rapidity with which they dissolve gold coatings from substrates. At a temperature as low as $200^{\circ} \mathrm{C}$, the dissolution rate of gold in the near-eutectic $\mathrm{Sn}-40 \mathrm{wt} \% \mathrm{~Pb}$ solder is $1 \mu \mathrm{m} / \mathrm{sec}$ [5], with the reaction continuing until either the gold is completely dissolved or the equilibrium composition is reached. This rapid dissolution is a major contributory factor to the exceptionally good wetting properties of gold and the ease of soldering to gold coatings [6]. This is illustrated by comparison with palladium coatings, which dissolve much more slowly in tin-lead solder, but at the same time are less readily wetted by it $[7,8]$. However, the high solubility of gold in the solder means that in practice, coatings less than about $2 \mu \mathrm{m}$ thick are completely dissolved in most soldering operations, resulting in the exposure of the bare substrate surface to the solder. This can lead to de-wetting, especially if there are oxides already present on the surface of the substrate or if these can form through the layer of molten solder.

On cooling from the soldering temperature, intermetallic phases are precipitated in several stages. For a dissolved gold content of up to approximately $15 \mathrm{wt} . \%$ at a typical bonding temperature of about $250^{\circ} \mathrm{C}$, cooling will generate the following precipitation sequence, as can be seen from the phase diagrams shown in Figure 1 [9]. First to solidify will be lead, together with the $\mathrm{AuSn}_{2}$ intermetallic compound. Unless cooling proceeds at a particularly high rate, the $\mathrm{AuSn}_{2}$ compound will react with the liquid on cooling to $210^{\circ} \mathrm{C}$, to form $\mathrm{AuSn}_{4}+\mathrm{Pb}$ and the last liquid fraction will solidify at $177^{\circ} \mathrm{C}$ in a eutectic reaction to form $\mathrm{AuSn}_{4}+\mathrm{Sn}+\mathrm{Pb}$. This means that the freezing temperature of solder that has dissolved a few per cent of gold is depressed by $12^{\circ} \mathrm{C}$.

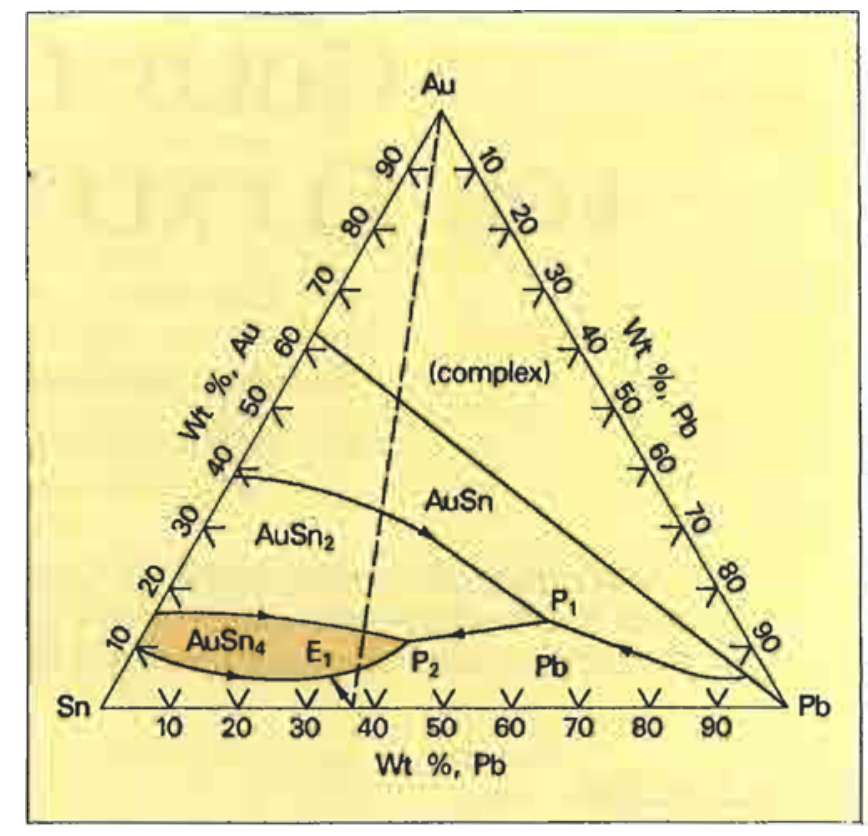

Fig. 1a Liquidus projection of the Au-Pb-Sn ternary system (after Humpston and Davies [9]). The first phase to form on solidification is labelled for each phase field

Contrary to claims in the literature $[6,10]$, no $\mathrm{AuPb}_{2}$ forms by reaction between eutectic $\mathrm{Sn}-\mathrm{Pb}$ solder and gold coatings: this is consistent with the $\mathrm{Au}-\mathrm{Pb}-\mathrm{Sn}$ ternary phase diagram, as can be appreciated from the liquidus projection of this system shown in Figure 1a [9]. However, consistent with the constitutional study [9], there is some solubility of lead in the $\mathrm{AuSn}_{4}$ compound in the solid state [11]. The $\mathrm{AuSn}_{4}$ intermetallic compound forms if the level of gold in the solder exceeds the solubility limit of $0.3 \mathrm{wt} \%$ at the freezing temperature [12]. Provided the gold content in the solder is less than $5 \mathrm{wt} \%$, this intermetallic compound precipitates as a dispersed minor phase $[13,14]$. However, when the concentration of gold exceeds this value, $\mathrm{AuSn}_{4}$ forms as a primary phase in the form of relatively large acicular (needle-like) platelets. The weak interface between these coarse anisotropic $\mathrm{AuSn}_{4}$ crystals and the solder matrix is the source of the embrittlement of tin-lead solders by gold, which is well documented in the literature [13-18].

In particular, Harding and Pressly [13] have shown that if the gold plating thickness on each of the two mating surfaces exceeds 1 per cent of the width of a joint made with eutectic $\mathrm{Sn}-37 \mathrm{wt} . \% \mathrm{~Pb}$ solder (i.e., the fraction of gold in the joint is greater than about $5 \mathrm{wt} . \%$ ), it detrimentally affects joint strength. This result is entirely consistent with those relating to the mechanical properties of bulk tin-lead alloys loaded with gold 


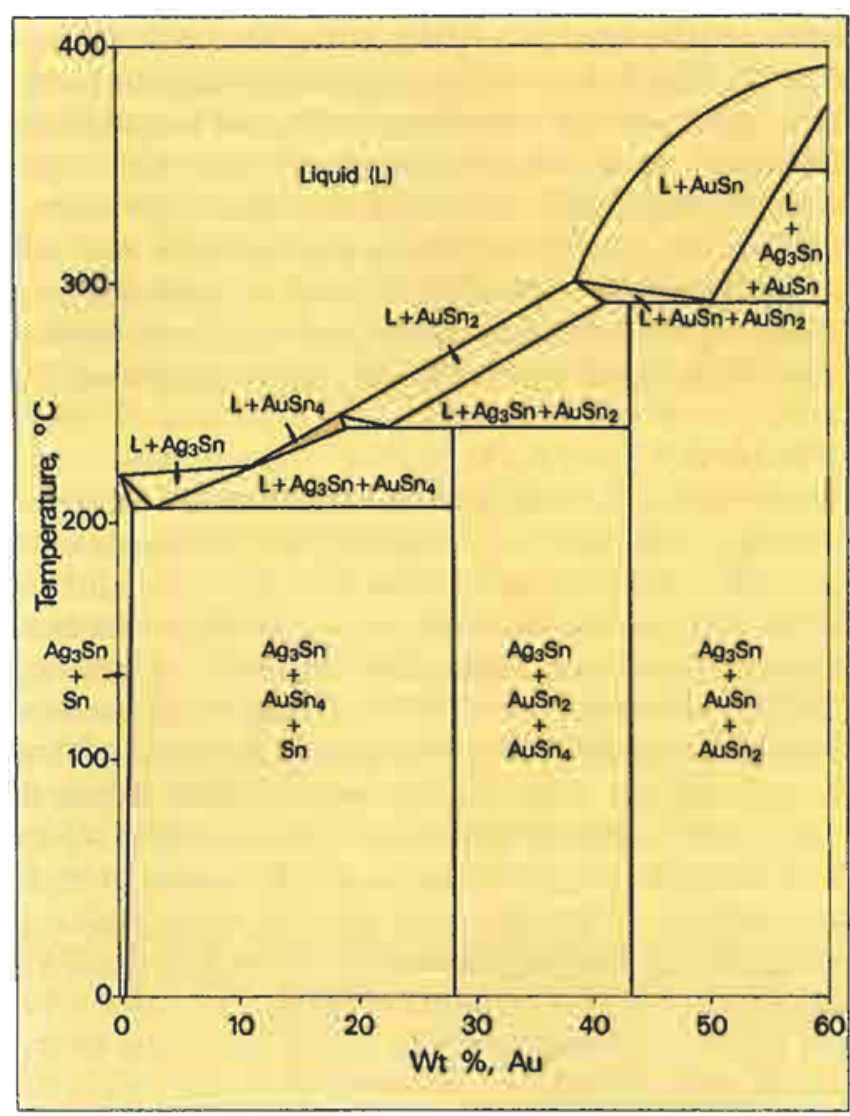

Fig 1b Vertical section in the Au-Pb-Sn ternary system between eutectic tin-lead (Sn-37wt.\% Pb) composition and gold. The plan view of this section is marked by a dotted line on the liquidus projection of the Au-Pb-Sn ternary system shown in Figure la

$[11,14]$, which show that the impact and shear strength of such alloys is not reduced until the gold fraction exceeds between 4 and $5 \mathrm{wt} . \%$. The shear strength, ductility and toughness of the bulk alloy actually increase for small percentage gold additions $[13,14]$.

By reducing the thickness of the gold coating to a degree that no significant amount of the $\mathrm{AuSn}_{4}$ compound forms, the embrittlement problem can be avoided. For a $50 \mu \mathrm{m}$ wide soldered joint, this coating would have to be under $0.5 \mu \mathrm{m}$. Gold coatings of this thickness applied by a wet plating method are porous and the underlying substrate is therefore susceptible to oxidation. Therefore the solderability of thin gold coatings on various metal substrates, including copper, deteriorates rapidly during storage $[17,19]$. However, it has been shown at the GEC Hirst Research Centre that sputter-deposited gold coatings as little as $0.3 \mu \mathrm{m}$ thick on a variety of metal substrates, including copper and chromium, are sufficiently pore free that they retain an adequate degree of solderability for several months.
Several fabrication processes have been successfully developed at the GEC Hirst Research Centre, using sputtered gold coatings together with tin-based solders. A buffer layer of silver or Sn-35wt.\% Ni between the substrate and a thin (porous) plating of gold has been found to preserve the solderability with rosin-based fluxes over very long periods $[20,21]$. This is presumably because corrosion products from these layers do not spread from the pores over the surface of the gold. It is not known whether this additional layer will provide the same benefit for vacuum soldering.

A different approach to overcoming the problem of joint embrittlement by gold has been to alloy the gold with elements that are capable of reducing the solubility or diffusion rate in the solder. Nickel is known to have a low rate of diffusion into tin and tin-lead alloys. It has been found that a white gold alloy plating of Au$15 \mathrm{wt} . \% \mathrm{Ni}$ forms a considerably reduced amount of the $\mathrm{AuSn}_{4}$ intermetallic compound with tin-lead eutectic solder and after ageing for four weeks at $110^{\circ} \mathrm{C}$, no growth of the intermetallic layer was observed. The formation of a tin-nickel intermetallic compound is thought to inhibit the diffusion of gold into the solder $[22,23]$. Shear strengths for lap joints on plated brass substrates were virtually constant for the gold-nickel coatings up to $5 \mu \mathrm{m}$ thick, and only above this value did the strength decline. However, the measured strengths for the thinner coatings were only about half that for a comparable pure-gold plating. In the work reported, it was found that the gold-nickel platings exhibited superior shelf life to pure gold. No further studies of this alloy coating have been reported.

Alloying additions to gold coatings are known to have a weakening effect on soldered joints. While it is evident that the solderability of gold platings is strongly influenced by the alloying addition, measured differences in solderability from one alloy coating to another vary according to the test used for assessment [2] Among the most useful results are those of Harding and Pressly [13], who measured shear strength as a function of soldering temperature for different types of gold coating. Cobalt-alloyed gold, in particular, produced significantly weaker joints. Ainsworth suggested that this effect might be due to either de-wetting on the alloyed surface or to high internal stress levels that are characteristic of such coatings, coupled with a stress arising from a volume change due to intermetallic compound formation [19]. However, it has been shown that the weaker joints formed to cobalt-alloyed gold coatings derive instead from organic matter co-deposited from the plating bath [3]. This organic material decomposes during the soldering operation to produce gas which 


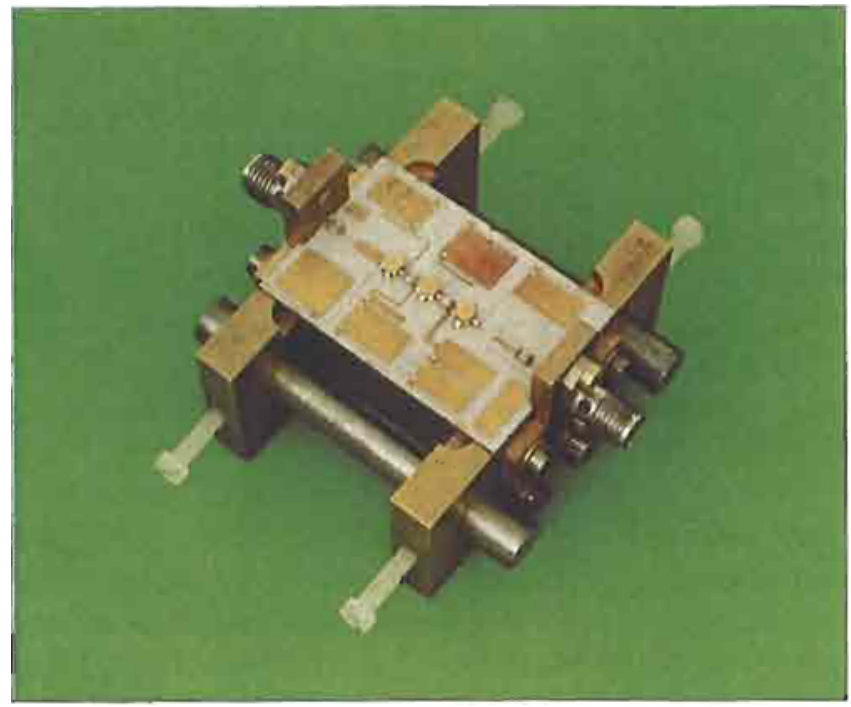

A microwave amplifier. Gold is used for most microwave printed circuit interconnects because of its good electrical properties and corrosion resistance - at microwave frequencies, electric current travels only through the surface layer in conductors. Because the circuit substrate is an insulating non-solderable material, any soldered joints made to the strip lines must be designed to ensure that the gold is not dissolved by the solder through to the substrate

gives rise to a highly porous and, therefore, weak soldered joint. It has been shown that coatings of gold alloyed with $33 \mathrm{wt}$.\% copper are more resistant to dissolution by tin-lead solders, although no data was obtained for a key parameter, namely joint strengths, using this metallization [6].

There is no significant difference in the behaviour and properties of tin-lead solders of composition 60:40 and 63:37 with regard to gold coatings. Reaction rates are slower with alloys containing low percentages of tin [19], but these solders have poorer wetting properties and no information is available on the mechanical properties of joints made to gold [21]. For tin contents in the range 20 to $50 \mathrm{wt} . \%$, much higher soldering temperatures are required and the reaction rates are correspondingly higher, offsetting the effect of the lower tin concentration.

\section{Tin-gold}

Two of the eutectic alloys formed between tin and gold find application as solders. The tin-rich eutectic alloy containing $10 \mathrm{wt} . \%$ gold $\left(\mathrm{m} . \mathrm{p} .=217^{\circ} \mathrm{C}\right)$ has been used for soldering to gold, but the high content of $\mathrm{AuSn}_{4}$ in the eutectic composition, means that joints made with this solder to gold coatings of any thickness will have poor mechanical strength [24]. As in the case of tin-lead solders, extensive erosion of the gold coating is to be expected in the vicinity of the joint. The other gold-tin eutectic alloy used as a solder is Au-20wt.\% Sn (m.p. = $278^{\circ} \mathrm{C}$ ). This alloy is not aggressive towards gold coatings, in conformity with the steep slope of the gold-rich liquidus curve, which means that the maximum solubility of gold is very small at any soldering temperature. At the same time, it wets gold surfaces well and produces strong joints [25]. Therefore, high integrity joints to gold surfaces can be expected with this solder, but it is an expensive choice and is not widely used.

\section{Tin-silver}

Tin-silver alloys of or close to the eutectic composition, $\mathrm{Sn}-3.5 \mathrm{wt} . \% \mathrm{Ag}\left(\mathrm{m} . \mathrm{p} .=221^{\circ} \mathrm{C}\right.$ ) are commonly used as solders. Dissolution of gold in these solders brings about a progressive depression of the melting point until the ternary eutectic temperature of $206^{\circ} \mathrm{C}$ is reached [26], as shown in Figure $2 b$. The ternary eutectic comprises primary tin together with $\mathrm{Ag}_{3} \mathrm{Sn}$ and $\mathrm{AuSn}_{4}$. It has been found in recent work at the GEC Hirst Research Centre that loading of bulk ingots of $\mathrm{Sn}-4 \mathrm{wt} . \% \mathrm{Ag}$ solder with additions of gold produces an increase in strength and hardness, at the expense of ductility, which is shown in Figure 3. A similar effect was noted for $\mathrm{Sn}-40 \mathrm{wt} . \% \mathrm{~Pb}$ solder. Up to a concentration of about 8 to $10 \mathrm{wt} . \% \mathrm{Au}$, the solder is characterized by a fine dispersion of the $\mathrm{AuSn}_{4}$ phase throughout the solder. However, when the level of gold in the solder reaches $10 \mathrm{wt} \%$, there is a sudden change in its properties, as shown in Figure 3,

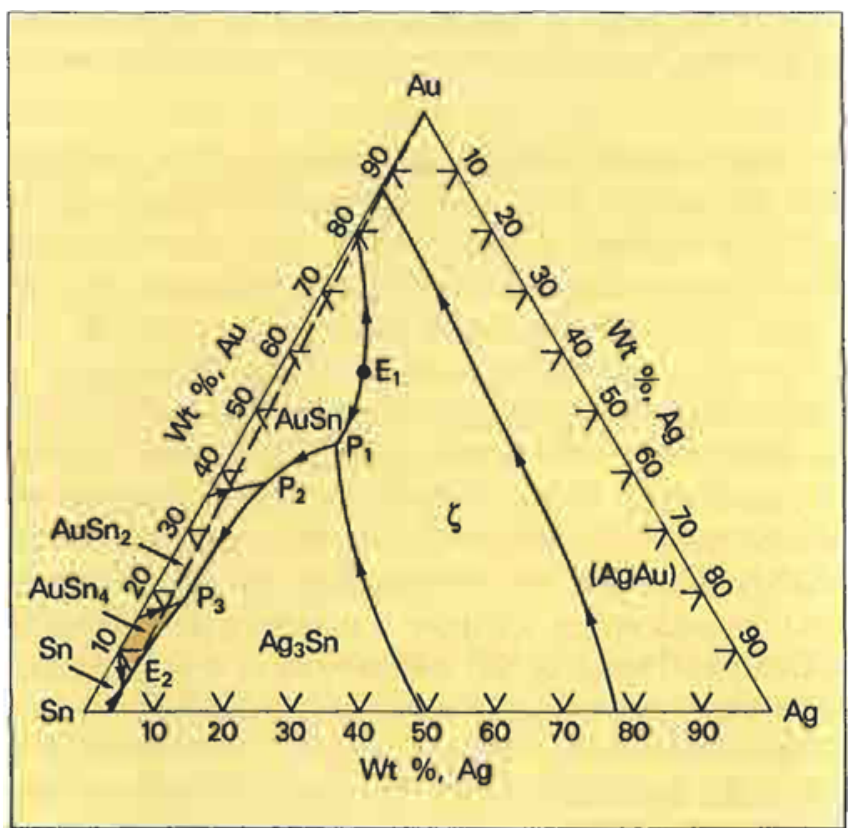

Fig. 2a Liquidus projection of the Ag-Au-Sn ternary system (after Evans and Prince [26]). The first phase to form on solidification is labelled for each phase field 
and the ingots become completely unworkable. This change corresponds to the precipitation of large platelets of primary $\mathrm{AuSn}_{4}$ intermetallic compound, as expected from the ternary Ag-Au-Sn phase diagram, for a concentration of gold in the solder of approximately 10 wt.\%, as shown in Figure 2a [26].

On this basis, it may be assumed that the maximum proportion of gold that can be tolerated in joints without producing significant embrittlement is about $10 \mathrm{wt} . \%$. This concentration would correspond to the complete dissolution of a gold plating on each of the two facing surfaces, amounting to $2.5 \%$ of the width of the joint, taking the density of the Sn- $4 \mathrm{wt} . \% \mathrm{Ag}$ solder as $8.5 \mathrm{Mg} \cdot \mathrm{m}^{-3}$ [27]. Thus, the $\mathrm{Sn}-4 \mathrm{wt} . \% \mathrm{Ag}$ solder is tolerant to approximately twice the volume fraction of gold as the $\mathrm{Sn}-40 \mathrm{wt} . \% \mathrm{~Pb}$ solder. Furthermore, in its mechanical properties, the tin-silver eutectic solder is generally superior to the tin-lead solder, especially with regard to its fatigue strength [27].

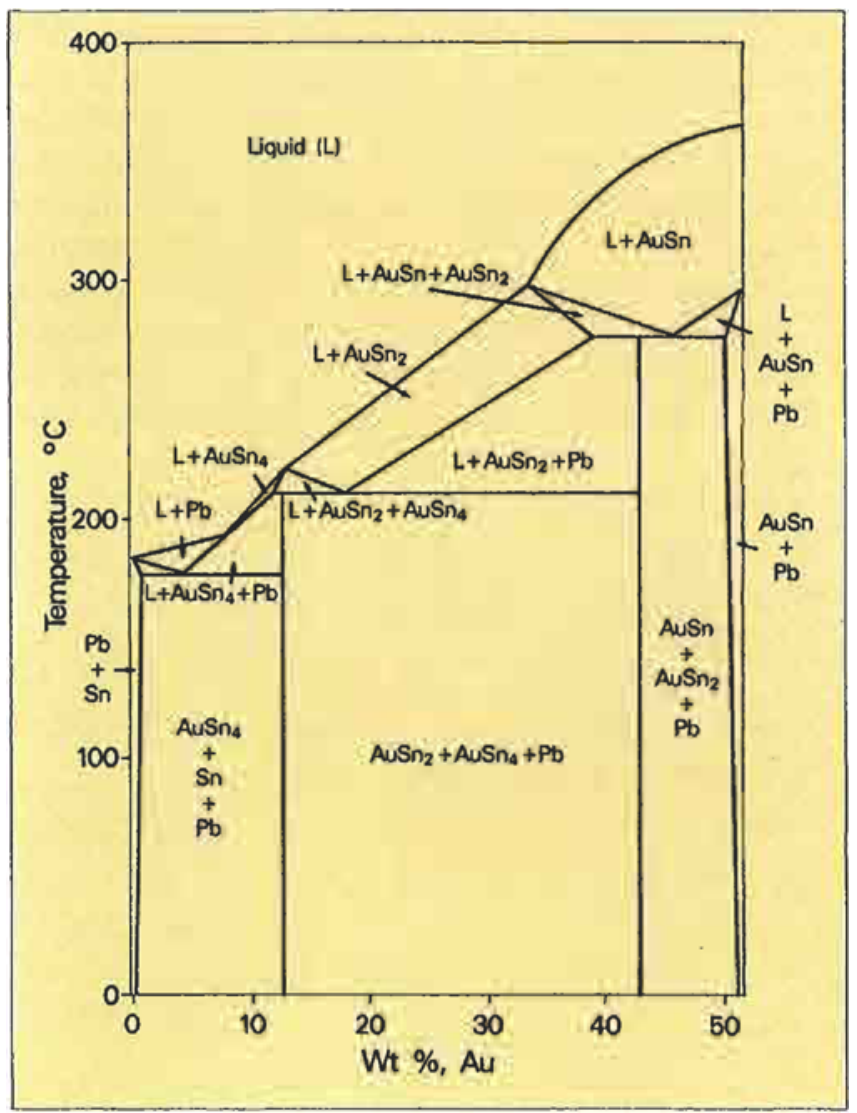

Fig. 2b Vertical section in the Ag-Au-Sn ternary system between eutectic tin-silver $(\mathrm{Sn}-3.5 \mathrm{wt} . \% \mathrm{Ag})$ alloy and gold. The plan view of this section is marked by a dotted line on the liquidus projection of the Ag-Au-Sn ternary system shown in Figure 2a

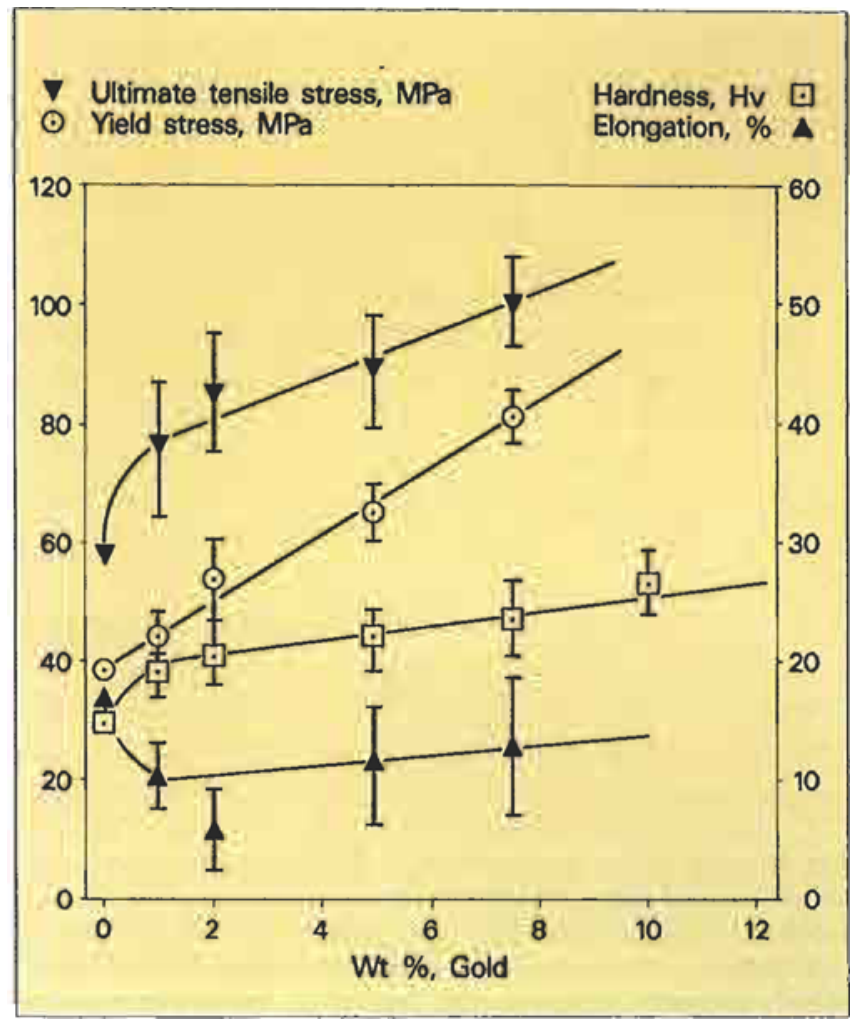

Fig. 3 A selection of mechanical properties of the $\mathrm{Sn}-4 \mathrm{wt} \% \mathrm{Ag}$ solder $\&$ gold, as a function of the gold addition. The mechanical properties of the pure solder are given in ref. 27

\section{Ternary tin-lead solders}

It has been noted that the dissolution of gold in the $\mathrm{Sn}-\mathrm{Pb}$ and $\mathrm{Sn}-\mathrm{Ag}$ solders lowers the melting points by as much as $15^{\circ} \mathrm{C}$ for the latter. This effect is even more marked in the case of the $\mathrm{Pb}-1.5 \mathrm{wt} . \% \mathrm{Ag}-1 \mathrm{wt} . \% \mathrm{Sn}$ solder, where the solidus temperature is reduced from $309^{\circ} \mathrm{C}$ to $217^{\circ} \mathrm{C}$ when $4 \mathrm{wt} . \%$ of gold is added, as ascertained in work carried out at the GEC Hirst Research Centre. Especially because this solder is generally selected for its relatively high melting point, it is important to be aware of this characteristic when using it for joining to gold-coated components. The dissolution of gold in solders does not necessarily depress theirmelting point. A contrary example that has been examined is the $\mathrm{Sn}-18 \mathrm{wt} . \% \mathrm{~Pb}-12 \mathrm{wt}$.\%In solder (m.p. = $136^{\circ} \mathrm{C}$ ), where a $5 \mathrm{wt.} \%$ gold addition raises its solidus temperature by $14^{\circ} \mathrm{C}$ to $150^{\circ} \mathrm{C}$.

\section{Tin-bismuth}

The reaction of tin-bismuth solders with gold is dominated by the formation of the embrittling $\mathrm{AuSn}_{4}$ intermetallic phase. The $\mathrm{Bi}-43 \mathrm{wt} . \% \mathrm{Sn}$ eutectic solder (m.p. $=139^{\circ} \mathrm{C}$ ) is used for low-temperature joining operations [28]. This solder is especially recommended 


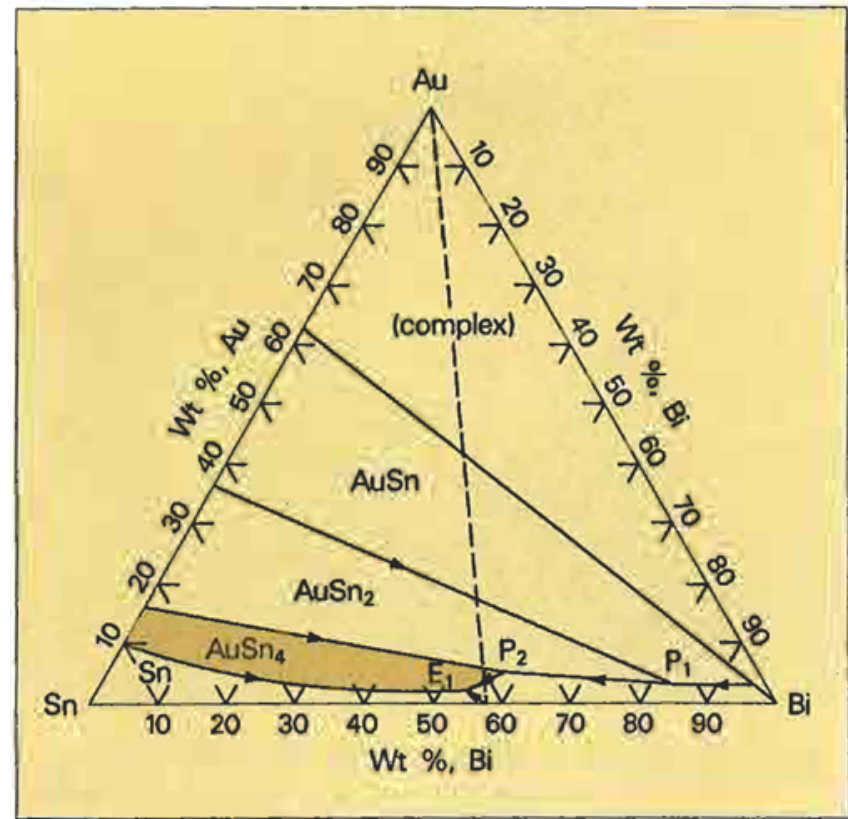

Fig. 4a Liquidus projection of the Au-Bi-Sn partial ternary system (after Maxwell [30]). The first phase to form on solidification is labelled for each phase field. AuSn forms a quasi-binary eutectic equilibriun with bismuth. Therefore, the reactions between Bi-Sn solders and gold coatings are restricted to the composition triangle AuSn-Bi-Sn, so that the complex reactions that occur in the gold-rich partial ternary system do not need to be considered

for making hermetic seals, because it has the unusual property of expanding slightly on solidification, thereby avoiding porosity due to shrinkage [29].

From a recent study of the gold-bismuth-tin ternary alloy system [30], it has been established that the dissolution of a mere $0.8 \mathrm{wt} \%$ of gold is sufficient to precipitate $\mathrm{AuSn}_{4}$ as the primary phase. Assuming a $50 \mu \mathrm{m}$ wide solder joint, this level of gold would correspond to just $0.1 \mu \mathrm{m}$ on each of the mating surfaces, taking the density of the $\mathrm{Bi}-43 \mathrm{wt} . \% \mathrm{Sn}$ solder to be $8.7 \mathrm{Mg} \cdot \mathrm{m}^{-3}$ [27]. Even with a high-integrity coating of gold applied by sputtering, at this thickness the coating is unlikely to be impervious to oxygen and its shelf life for solderability would therefore be fairly short.

It has been established that the dissolution of gold depresses the melting point of the Bi- 43 wt. \% Sn solder by just $2^{\circ} \mathrm{C}$. The liquidus projection of the $\mathrm{AuSn}-\mathrm{Bi}-\mathrm{Sn}$ partial ternary system is shown in Figure $4 a$, and a vertical section between $\mathrm{Bi}-43 \mathrm{wt} . \% \mathrm{Sn}$ and $\mathrm{Au}$ is presented in Figure $4 b$ [30].

Just as the presence of bismuth does not inhibit the formation of the embrittling $\mathrm{AuSn}_{4}$ intermetallic compound, neither does antimony, the neighbouring group element in the periodic table [17]. Similar considerations therefore apply to the use of bismuth-tin and antimony-tin alloys as to tin-lead when soldering to gold-coated items.

\section{Other Tin-based Solders}

Tin-based solders containing elements other than, or in addition to, lead have been studied in connection with gold coatings more than $1 \mu \mathrm{m}$ thick to ascertain whether these elements reduce the amount of brittle $\mathrm{AuSn}_{4}$ formed. Duckett and Ackroyd [17] have investigated a series of alloys of tin with various metals, including silver, antimony, bismuth, cadmium, copper, zinc, nickel and cobalt. Of these elements, only cadmium gave a noticeable reduction in the rate of dissolution of gold coatings and higher measured peel strengths on overlap joints, but the effect was not entirely reproducible.

\section{Design Guidelines for Fluxless Soldering with Tin-based Solders}

It has been noted that for each of the tin containing solders discussed above, there is a well-defined limit to the relative amount of gold that can be used as a

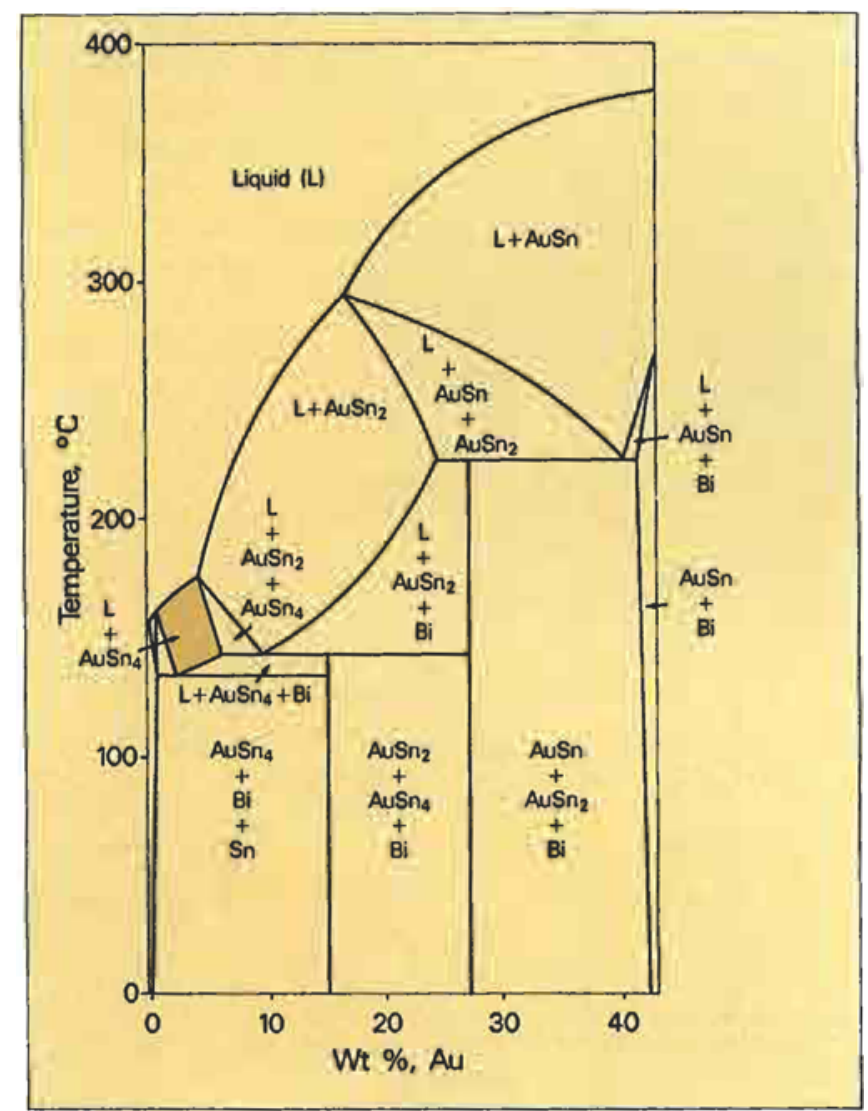

Fig. 4b Vertical section in the Au-Bi-Sn ternary system between eutectic bismuth-tin (Bi-43wt.\% Sn) alloy and gold. The plan view of this section is marked by the dotted line on the liquidus projection of the Au-Bj-Sn ternary system shown in Figure $4 \mathrm{a}$ 
solderable metallization without embrittling the joint through the formation of $\mathrm{AuSn}_{4}$ as the primary phase. Higher levels of gold incorporated into the solder can lead to the formation of the $\mathrm{AuSn}_{2}$ intermetallic compound, but the available evidence indicates that this does not ameliorate the solder embrittlement [11]. Because the critical proportion of gold is essentially a function of the quantity of tin in the joint, it follows that the maximum permissible level of gold actually rises with increasing fraction of tin in the solder, as can be seen in Table I. The percentage of gold needed to form the $\mathrm{AuSn}_{4}$ intermetallic compound as the primary phase on solidification is shown in the table for three of the tin alloys that have been considered in detail, and also for pure tin.

When heated to the soldering temperature, each of these solders will endeavour to dissolve a proportion of gold that corresponds to the equilibrium concentration for that alloy. Because dissolution occurs rapidly, in general this fraction of gold can be completely dissolved during a vacuum soldering operation. The percentage value of gold required to saturate the various solders at $50^{\circ} \mathrm{C}$ superheat is shown in Table I. In each case, the value is approximately three times the maximum level that does not produce joint embrittlement.

It follows that the problem of embrittlement by gold can only be avoided by limiting the coating thickness, as indicated above. However, this constraint needs to be balanced against the need for a sufficiently thick layer of gold to satisfy shelf life requirements. In the case of the Sn-40wt.\%Pb and the Sn-4wt.\%Ag solders, the appropriate coating conditions can be achieved by high- quality vapour deposition methods. However, for the Bi$47 \mathrm{wt} \% \mathrm{Sn}$ solder, the maximum permissible coating thickness of $0.1 \mu \mathrm{m}$ is too thin to guarantee a shelf life of more than a few days and it is therefore necessary to ensure that soldering operations are carried out using freshly coated components.

A general point to be aware of, and which was highlighted in connection with each of the tin-based solders mentioned, is that the dissolution of gold will invariably alter the freezing point of the solder: The change in the melting point of the three binary tin-based solders considered here, when these contain more than about $1 \mathrm{wt} . \%$ gold, is given in Table I.

\section{Solders Based on Indium}

Indium-lead, indium-tin and indium-lead-tin alloys are used as solders for joining gold-coated electronic components. Gold is less soluble in these alloys than in tin-lead solders as indicated by the relevant constitutional diagrams. It has been reported that a $6 \mu \mathrm{m}$ coating of gold takes 15 minutes to completely dissolve in the In-50wt. $\% \mathrm{~Pb}$ solder at $250^{\circ} \mathrm{C}$ [31].

Some work has been carried out at the GEC Hirst Research Centre to clarify the reaction that occurs between molten indium and gold metallizations. This has established that the compound $\mathrm{AuIn}_{2}$ forms as a continuous interfacial layer between indium, when heated above its melting point of $157^{\circ} \mathrm{C}$, and a gold coating, in a matter of seconds. Once established, this interfacial layer acts as an effective barrier between the indium and the gold because dissolution of the gold appears to

\section{Table I}

The Effect of Gold on Common Tin-based Eutectic Solders and Pure Tin

\begin{tabular}{|c|c|c|c|}
\hline $\begin{array}{c}\text { Solder composition } \\
\text { in wt.\% }\end{array}$ & $\begin{array}{c}\text { wt.\% of gold to form } \\
\text { AuSn4 as the } \\
\text { primary phase }\end{array}$ & $\begin{array}{c}\text { wt.\% of gold that will } \\
\text { dissolve in solder } \\
\text { at } 50^{\circ} \mathrm{C} \text { superheat }\end{array}$ & $\begin{array}{c}\text { Change in melting point } \\
\text { of solder by dissolving } \\
1 \text { wt.\% gold, }{ }^{\circ} \mathrm{C}\end{array}$ \\
\hline $\mathbf{5 7 B i - 4 3 S n}$ & 0.8 & 4 & -2 \\
$60 \mathrm{~Pb}-40 \mathrm{Sn}$ & 5 & 13 & -12 \\
$96 \mathrm{Sn}-4 \mathrm{Ag}$ & 10 & 30 & -15 \\
Pure Sn & 10 & 30 & -15 \\
\hline
\end{tabular}

Note: These values are derived from experimentally determined constitutional data reproduced in Figures 1, 2 and 4. They are subject to possible minor adjustment when these alloy systems are thermodynamically assessed. 


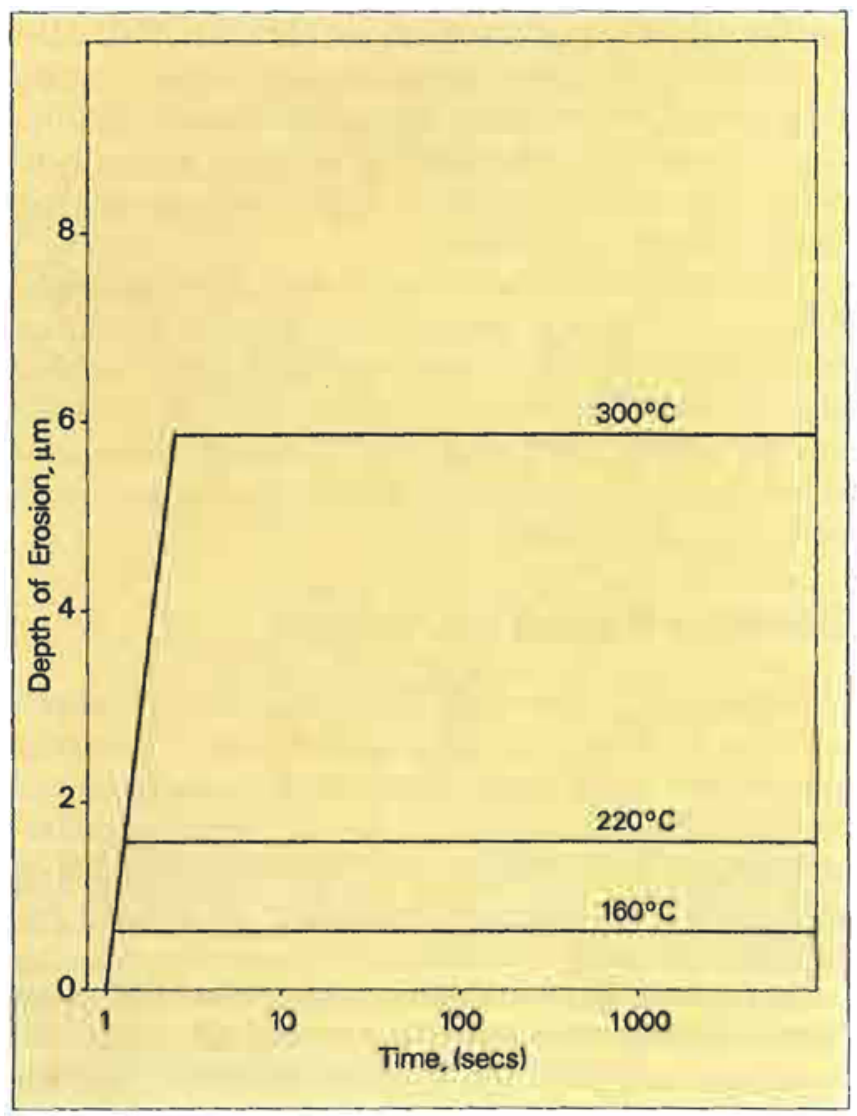

Fig. 5 Erosion of gold by indium, as a function of time and temperature

cease, at least over the ten-minute timescale that was investigated. The extent to which the gold coating has eroded when this self-limiting condition is achieved is a function of the soldering temperature, as shown in Figure 5.

Studies on the reaction between the $\mathrm{Pb}-50 \mathrm{wt}$.\% In and $\mathrm{Pb}-37.5 \mathrm{wt} . \% \mathrm{Sn}-25 \mathrm{wt} . \%$ In solders and gold have also been reported. Over the much longer timescales over which the experiments were conducted, the reaction did not tail off but continued, albeit at a slow rate, with the layer of $\mathrm{AuIn}_{2}$ intermetallic compound growing approximately linearly with time, down to temperatures as low as $50^{\circ} \mathrm{C}[32,33]$. Thus, at $160^{\circ} \mathrm{C}$, the reaction layer grows at an approximately constant rate of $1.64 \mu \mathrm{m} / \mathrm{hr}$ [32]: no gold-tin intermetallic compound was detected in the reaction between gold and the lead-tin-indium solder.

The different timescales employed in the study of the layer growth between gold and indium and in those involving the lead-containing solders, makes proper comparison of the results somewhat difficult. However, the self-limiting reaction that has been claimed to occur between indium and gold is not necessarily contradicted by the reported results on the layer growth between the $\mathrm{Pb}-\mathrm{In}$-(Sn) solders and gold coatings. This is because the reaction layer in the latter cases does not consist of pure gold-indium intermetallic, as when gold reacts with pure indium across an interface, but comprises two phases. These phases take the form of separate grains of the AuIn $\mathrm{n}_{2}$ compound entirely embedded in primary lead [32]. The lead phase provides a short diffusion path between the solder and the gold coating and permits the reaction to continue. There is no evidence that the $\mathrm{AuIn}_{2}$ intermetallic compound produces joint embrittlement, so that the complete transformation of gold metallization to this reaction phase and primary lead through ageing need not be any cause for concern. However, in the situation where the solder filled joint is extremely thin-less than about $15 \mu \mathrm{m}$-and the gold layer is thicker than about $10 \mu \mathrm{m}$, indium depletion in the solder will also occur on prolonged ageing. Then, a second intermetallic compound will form adjacent to the gold, namely $\mathrm{Au}_{9} \mathrm{In}_{4}$ [32]. It has been suggested that this particular intermetallic compound might embrittle the joint, so that it may be a worthwhile precaution to prevent the formation of this phase by ensuring that the volume ratio of indium to gold in the joint is higher than about $2: 1$. The self-limiting characteristic of the reaction would guarantee that the gold metallization is not breached, provided that the soldering operation is carried out at a temperature not much higher than $50^{\circ} \mathrm{C}$ above the melting point of the solder, which is consistent with standard practice. For a typical joint, having a gap $20 \mu \mathrm{m}$ or more wide, the maximum thickness of the gold plating applied to each of the two facing surfaces should be about $5 \mu \mathrm{m}$. This compares with a gold coating thickness of less than $0.5 \mu \mathrm{m}$ when tin-based solders are used. As mentioned earlier, a pore-free layer of gold $5 \mu \mathrm{m}$ thick can be readily deposited by standard electroplating methods.

The joints made with indium-based solders, in particular those containing lead, tend to be relatively soft, and have much lower strengths than those made with tin-lead solders $[31,32]$, but the fatigue resistance of the former are significantly greater, with the fatigue life being typically two orders of magnitude higher [34].

\section{Other Solders}

\section{Lead-bismuth}

The $\mathrm{Pb}-43 \mathrm{wt} . \% \mathrm{Bi}$ eutectic alloy (m.p. $=125^{\circ} \mathrm{C}$ ), like the $\mathrm{Bi}-43 \mathrm{wt} . \% \mathrm{Sn}$ alloy, is used as a low-temperature solder [28]. The reactions occurring between bismuthlead and gold have not been as well characterized as they have been for bismuth-tin. The shear strength of joints 
made with $\mathrm{Pb}-43 \mathrm{wt}$ \% Bi solder to gold-coated components is less than that using $\mathrm{Sn}-37 \mathrm{wt}$. $\mathrm{Pb}$ and the wetting and spreading characteristics of this solder on gold are considerably inferior to those of tin-lead [25].

\section{Gold-germanium and Gold-silicon}

The gold-germanium and gold-silicon eutectic alloys (Au-12.5wt.\%Ge, m.p. $=361^{\circ} \mathrm{C}$ [35]; Au-18.6wt.\%Si, m.p. $\left.=363^{\circ} \mathrm{C}[36]\right)$ are used as high melting point solders in electronics fabrication. They wet gold-coated surfaces well but, because the liquidus curve of the gold-rich side of the phase diagram is steep, they are not particularly aggressive to them. However, the gold-germanium and gold-silicon alloys readily oxidize and the eutectic composition is brittle, but these problems are overcome by producing foils of hypo-eutectic composition, i.e. rich in gold. Their costliness, stemming from their high gold content, tends to act as a disincentive for the use of these alloys.

\section{Conclusions}

Gold coatings are widely used to promote solderability and, when soldering in a vacuum or protective atmosphere, they provide a functional substitute for fluxes.

While aiding wetting and spreading by the solder, gold dissolves readily in tin-based solders, which can result in the total erosion of the coating and in the formation of the $\mathrm{AuSn}_{4}$ intermetallic compound. This phase is a common source of embrittlement in soldered joints.

This problem may be avoided by limiting the gold coating to a thickness of $0.5 \mu \mathrm{m}$ or less in a typical joint that is $50 \mu \mathrm{m}$ wide. If the coating is applied by a physical vapour deposition method, notably sputtering, it can be produced essentially pore-free and therefore capable of a storage life of several months. Another solution that has been proposed involves alloying the gold with elements such as nickel that will reduce the dissolution of the coating in the solder:

Gold is generally less soluble in indium-based solders, and these are used for joining to components with gold platings thicker than $0.5 \mu \mathrm{m}$. However, these solder's and the joints made with them are relatively weak.

Bismuth-containing solders generally wet and spread less well on gold surfaces than the tin-lead alloys. If these solders contain tin, the gold will dissolve and the embrittling $\mathrm{AuSn}_{4}$ compound will form, unless the coating is so thin that it is unlikely to be pore-free and so have an assured shelf life, even when applied by a

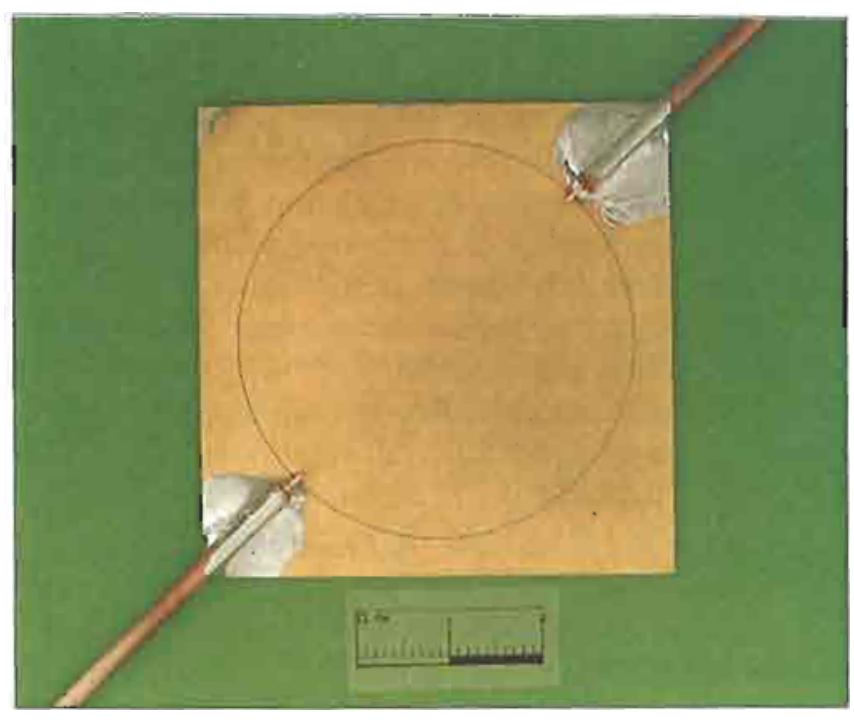

A ceramic transducer that has been sputter metallised with a reactive metal and then protected from oxidation with a thin layer of sputtered gold. Sputtered gold is used in place of a plating so that only a thin layer is required for hermeticity and, therefore, does not unduly alter the char acteristics of the transducer. Soldered connections have been made to the opposing coruers of the device

high-integrity vapour deposition process.

The high-gold eutectic alloys with germanium, silicon and tin are comparatively unaggressive towards gold, and are suitable as high melting point solders for vacuum joining gold-coated components.

The alloy constitution of the above-mentioned solders with gold is adequately established to describe and explain the metallurgical reactions that occur in these alloy systems.

\section{Acknowledgements}

The contributions of Dr K.B. Guy and Dr D.S. Evans, both formerly of the GEC Hirst Research Centre, are gratefully acknowledged, in particular with regard to the derivation of the data shown in Figures 3 and 5. The World Gold Council and the General Electric Company are acknowledged for their support of this study.

\section{Abstract}

The available information on soldering to gold coatings is reviewed, with particular reference to flux-free joining in a vacuum, a method that is widely used in electronics fabrication. In this process, the gold coating provides a substitute for the flux, ensuring that the surfaces of the joint are oxide free and solderable. Gold has outstanding wetting properties but at the same time 
it dissolves rapidly in many solders, especially those containing tin, to form intermetallic compounds. In certain cases, these compounds give rise to joint embrittlement. Means of overcoming this problem, which are described in the literature or which have been developed within the framework of the bonding activities at the GEC Hirst Research Centre, are described.

The characteristic behaviour of solders based on tin, indium, bismuth and other metals with gold substrates is assessed and compared. Recent progress that has been made in elucidating the alloy constitution of gold-solder systems is highlighted and technologies that have become available for successfully exploiting gold coatings in vacuum soldering are noted.

\section{References}

1 H.H. Manko, 'Solders and Soldering' (2nd ed.), New York, 1979, pp. 17-18

2 C.J. Thwaites, 'Some aspects of soldering gold surfaces', Electroplat. Met. Finish., 1973, 26(8) $10-15$

3 C.J. Thwaites, 'Some aspects of soldering gold surfaces', Electroplat. Met. Finish., 1973, 26(9), $21-26$

4 G.M. Green, 'The soft soldering of gold plated surfaces. A review', STL Report No. MEC/R446/1974/806, March 1974

5 W.G. Bader, 'Dissolution of $\mathrm{Au}, \mathrm{Ag}, \mathrm{Pt}, \mathrm{Cu}$ and $\mathrm{Ni}$ in a molten tin-lead solder', Welding J., Res. Suppl., $1969,48,551 S-57 S$

6 H. Heinzel and K.E. Saeger', 'The wettability and dissolution behaviour of gold in soft soldering', Gold Bull., 1976, 9(1), 7-11

$7 \mathrm{~J}$. Whitfield and A.J. Cubbin, 'Experimental observations on the effect of gold and palladium on soldered joints', ATE J., 1965, 21(1), 2-10

8 R.D. Berry and R.W. Johnson, 'The soldering of palladium-coated and gold-coated surfaces', Proc. Inst. Welding, Autumn Meeting, 1964, 9.1-9.4

9 G. Humpston and B.L. Davies, 'Constitution of AuSn-Pb-Sn partial ternary system', Mater. Sci. Technol., 1985, 1, 433-42

10 H.H. Manko, ref. 1, 69

11 M.H. Bester, 'Metallurgical aspects of soldering gold and gold plating', Proc, Inter/Nepcon, 1968, Brighton, Chicago 1969, 211-31

$12 \mathrm{~A}$. Prince, 'The $\mathrm{Au}-\mathrm{Pb}-\mathrm{Sn}$ ternary system', J. Less-Common Met., 1967, 12, 107-16

13 W.B. Harding and H.B. Pressly, 'Soldering to gold plating', Am. Electroplat. Soc., 50th Annu. Proc., 1963, 90-106

14 R.N. Wild, 'Effects of gold on the properties of solders', 1BM Federal Systems Div, Owego, Rep. No. 67-8252157, Jan. 1968
15 W.A. Mulholland and D.L. Willyard, 'Soldering to thin film hybrid microcircuits', Welding J., Res. Suppl., 1974, 54(10), 466s-74s

16 H.P. Kehrer and E.M. Wenzel, 'Weichlöten von Goldoberflächen in der Elektrotechnik', Metall, 1979, 33(10), 1047-51

17 R. Duckett and M.L. Ackroyd, 'The influence of solder composition on the embrittlement of soft-soldered gold coatings', Electroplat. Mel. Finish, , 1976, 29(5), 13-20

18 F.G. Foster, 'Embrittlement of solder by gold from plated surfaces', ASTM Spec. Publ. No. 319, 1963. 13-19

19 P.A. Ainsworth, 'Soft soldering on gold coated surfaces', Gold Bull., 1971, 4(3), 46-50

20 A.W. Castillero, 'Gold coating to improve solderability on tin-nickel', Met. Finish., 1964, 62(2), 61

21 G.C. Wilson, 'The use of tin when alloyed with nickel or lead as a printed circuit finish', Trans. Inst. Met. Finish., 1972, 50(3), 109-13

22 W.K. Lee, 'Improvement of solder connections by gold alloy plating', Plating, 1971, 58(10), 997-1001

23 P.A. Ainsworth, 'Gold diffusion and soft soldering', Gold Bull., 1972, 5(2), 37

24 J.I. McLeod and D.R. Wallis, 'Examination of 90:10 tin: gold alloy solder joints', HRC Metall. Div, Rep. 2005/M, Sept. 1970

25 D.H. Brewer, 'Solders for thick gold plating', Welding J, Res. Suppl., 1970, 49(10), 465-70

26 D.S. Evans and A. Prince, "Thermal analysis of the $\mathrm{Ag}-\mathrm{Au}-\mathrm{Sn}$ ternary system in the region from 20 to $100 \%$ Sn', Met. Sci., 1974 8, 286- 90

27 'Solder alloy data. Mechanical properties of solders and soldered joints', Int. Tin Res. Inst. Publ. No. 656, London, 1986

28 R. Strauss and S. Smernos, 'Low temperature soldering', Bull. Bismuth Inst., 1986, 49, 1-4

29 K.S. Dogra, 'A bismuth tin alloy for hermetic seals', Bull. Bismuth Inst., 1987, 52, 8-10

30 C.A. Maxwell, 'Study of the phase relations in the AuSn-Bi-Sn partial ternary system', MSc Thesis, Manchester University and UMIST, 1986

31 F.G. Yost, 'Soldering to gold films', Gold Bull., 1977, 10(4), 2-7

32 F.G. Yost, F.P. Ganyard and M.M. Karnowsky, 'Layer growth in Au-Pb/In solder joints', Met. Trans. A., 1976, 7A(8), $1141-48$

33 J.D. Braun and T.B. Rhinehammer, 'An investigation of the reaction between pure gold wire and lead-tinindium solder', Trans. ASM, 1963, 56, 870-74

34 C.R. Jackson, 'Lead-indium solder alloy won't embrittle in gold', Circuits Manuf., 1973, 1, 40-41

$35 \mathrm{H}$. Okamoto and T.B. Massalski, 'The Au-Ge (gold germanium) system', Bull. Alloy Phase Diagrams, $1984,5(6), 601-10$

36 H. Okamoto and T.B. Massalski, 'The Au-Si (goldsilicon) system', Bull. Alloy Phase Diagrams, 1983, 4(2), 190-98 